\title{
Conceptus-related measurements at early pregnancy in Black Bengal goat: an abattoir study
}

\author{
Anup K. Talukder ${ }^{1, *}$, Mohammad A. Rahman ${ }^{2}$, Mohammad N. Hoque ${ }^{1}$, Mohammad T. Islam², \\ Abu N. M. A. Rahman ${ }^{1}$ and Ziban C. Das $^{1}$ \\ ${ }^{1}$ Department of Gynecology, Obstetrics \& Reproductive Health, Faculty of Veterinary Medicine \& Animal Science, \\ Bangabandhu Sheikh Mujibur Rahman Agricultural University, Gazipur 1706, Bangladesh \\ ${ }^{2}$ Department of Surgery \& Radiology, Faculty of Veterinary Medicine \& Animal Science, Bangabandhu Sheikh Mujibur \\ Rahman Agricultural University, Gazipur 1706, Bangladesh \\ ${ }^{3}$ Department of Pathobiology, Faculty of Veterinary Medicine \& Animal Science, Bangabandhu Sheikh Mujibur Rahman \\ Agricultural University, Gazipur 1706, Bangladesh
}

Received April 9, 2020

Revised June 2, 2020

Accepted June 6, 2020

\section{*Correspondence}

Anup K. Talukder

E-mail: anupbau@bsmrau.edu.bd

ORCID

https://orcid.org/0000-0001-6904-8801
ABSTRACT The present study aimed to investigate the conceptus-related changes during early pregnancy in the Black Bengal breed of goat. A total of 22 gravid genitalia of the Black Bengal goats were collected from local slaughterhouses. The crown-rump lengths (CRL) of the conceptuses were determined to estimate the gestational age (GA). The length and diameter of uterine horn and amniotic sac were measured, and volume of amniotic and allantoic fluid formed by individual conceptus were recorded. The results reveal that the $C R L$ is positively correlated with GA of the conceptus $\left(R^{2}=0.89\right.$, $p<0.05$ ); however, CRL was not influenced by number of conceptus. Both the left and the right uterine horn gradually increased in size with the advancement of pregnancy irrespective of conceptus number present in the horn. The size of the amniotic sac of conceptus gradually increased with the conceptus age but maintained spherical shape from 5 to 7 weeks of pregnancy. The amniotic fluid formed by individual conceptus rapidly increased from 5 weeks $(3.4 \pm 0.3 \mathrm{~mL})$ to 7 weeks $(21.0 \pm 2.0 \mathrm{~mL})$ and 9 weeks $(111.5 \pm 4.0 \mathrm{~mL})$. The volume of allantoic fluid formed by individual conceptus was steadily increased until 7 weeks $(60.0 \pm 5.0 \mathrm{~mL})$ and began to decline slowly thereafter $(50.0 \pm 5.0 \mathrm{~mL}$ at 9 weeks). Notably, there was no effect of conceptus number per pregnancy on individual amniotic and allantoic fluid volume. The cotyledons have first appeared on the allanto-chorionic surface from 4 to 5 weeks of pregnancy. The closed eye, nostril and hooves of the conceptus became visible at 7 weeks of pregnancy. The present study has shown the basic information on conceptus-related developmental changes during early pregnancy up to 9 weeks in Black Bengal goat.

Keywords: amniotic and allantoic fluid, Black Bengal goat, conceptus, early pregnancy, uterine horn

\section{INTRODUCTION}

The Black Bengal goat is the only recognized goat breed and considered as poor man's cow in Bangladesh, which plays an important role for economy of the rural community. Till date, it is the only source of income for 
poor women and contributes to improve their livelihood in Bangladesh. There are about 26.1 millions of goats in Bangladesh (Bangladesh Economic Review, 2018), of which $90 \%$ are Black Bengal goat (Capra hircus). The black Bengal goat farming has got popularity in Bangladesh because of their adaptability, disease resistance, delicacy of meat, and superior skin quality (Hussain et al., 1996; Chowdhury et al., 2002). In addition, because of their small size they are easy to rear, require least amount of resources and provide high economic returns.

Reproductive performance is economically important because of its effect on the number of offspring produced per year in the goat (Greyling, 2000). Interestingly, Black Bengal breed of goat attains early sexual maturity, gives birth twice in a year and has high prolificacy (Chowdhury et al., 2002), which clearly indicate the importance of this type of goats to the goat owners/farmers in Bangladesh. Fertilization is the first step of pregnancy that occurs in the oviduct. Following fertilization, goat embryo undergoes through a series of mitotic division (cleavage) and simultaneously travels down the oviduct to the uterus. The goat conceptus then develops gradually inside the mother' s womb for about 150 days in which many physiological changes occur in the conceptus with the advancement of pregnancy period (Mellado et al., 2000). These crucial changes are related to the normal growth and development of the conceptus leading to birth of healthy kids (Argüello, 2011). Thus, it is very important to study the gradual development of goat conceptus to differentiate normal pregnancy from abnormal one, to estimate the conceptus age and number of conceptus per pregnancy. Until recently, changes in conceptus development during early pregnancy particularly in Black Bengal goat remains poorly understood. The present study was, therefore, aimed to investigate the gradual changes in conceptus development during early pregnancy period in Black Bengal goats.

\section{MATERIALS AND METHODS}

\section{Collection and transportation of genitalia}

A total of 22 genital tracts of pregnant Black Bengal goats were collected from local slaughterhouses of Gazipur City Corporation, Gazipur, Bangladesh. The genital tracts were transported to the laboratory in an ice box maintaining $4-8^{\circ} \mathrm{C}$.

\section{Biometric measurements}

In the laboratory, genitalia were cleaned and freed from adjacent tissues and kept on the dissection table in normal position. The biometric parameters (length and diameter) of uteri were determined using measuring scale and slide calipers according to a previously described protocol (Talukder et al., 2015). The uteri were carefully dissected and conceptus enclosed in chorio-allantoic sac was taken out and kept in a tray. First, allantoic sac was incised and resultant allantoic fluid was taken in measuring cylinder to record the volume. The length and diameter of amniotic sac were measured by using slide calipers. Amniotic sac was ruptured by pinching with needle and resultant fluid was measured. Finally, the approximate age of the conceptus was determined by measuring crown-rump length (CRL) as described earlier (Martínez et al., 1998; Amer, 2008). Conceptuses were also examined for the presence of cotyledons, fetal eye, hooves and ribs.

\section{Statistical analysis}

The data analysis was performed using Statistical Packages for Social Sciences software, version 14.0 for windows (SPSS, Inc., Chicago, IL, USA). Descriptive statistics were applied to present the data. All data are presented as mean \pm SD. Regression analysis was carried out to elucidate the relationship between crown-rump length of conceptus and progress of pregnancy period. $p<0.05$ was considered statistically significant.

\section{RESULTS}

The mean crown-rump length (CRL) of fetus was $0.6 \pm$ $0.1 \mathrm{~cm}$ at 3 weeks of pregnancy. Then, it increased gradually with the progress of pregnancy period and recorded $9.1 \pm 0.6 \mathrm{~cm}$ at 9 weeks of gestation (Fig. 1A). The CRL is positively correlated with gestational age of conceptus $\left(\mathrm{R}^{2}=0.89, p<0.05\right)$ (Fig. 1B); however, it was not influenced by number of conceptus per pregnancy.

There was no difference observed in uterine length and diameter between the left and the right uterine horn until 5 weeks of pregnancy irrespective of number of conceptus present in each horn (Table 1). However, the length of the right uterine horn was higher than that of the left horn at 5 weeks of pregnancy and the vice-versa was observed at 9 weeks of pregnancy. The diameters of both the uterine horns was notably increased from 5 weeks and onwards. 
A

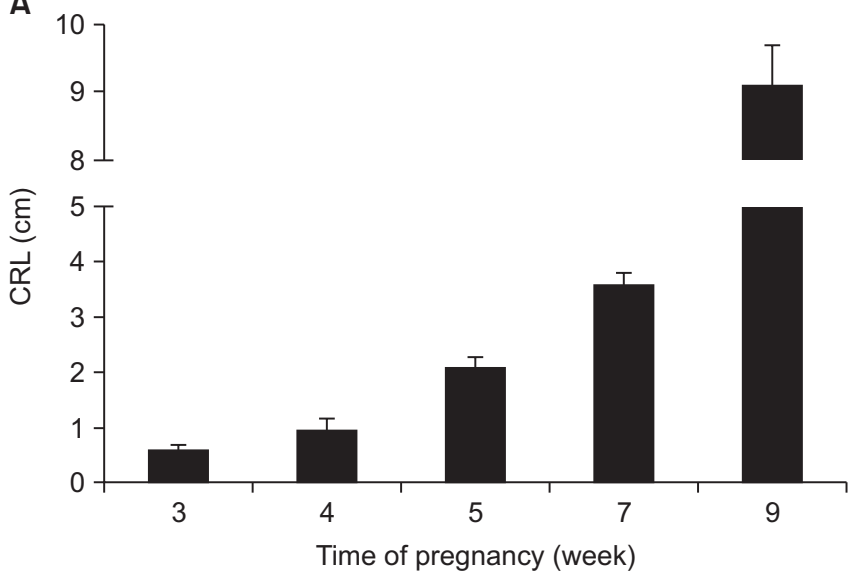

B

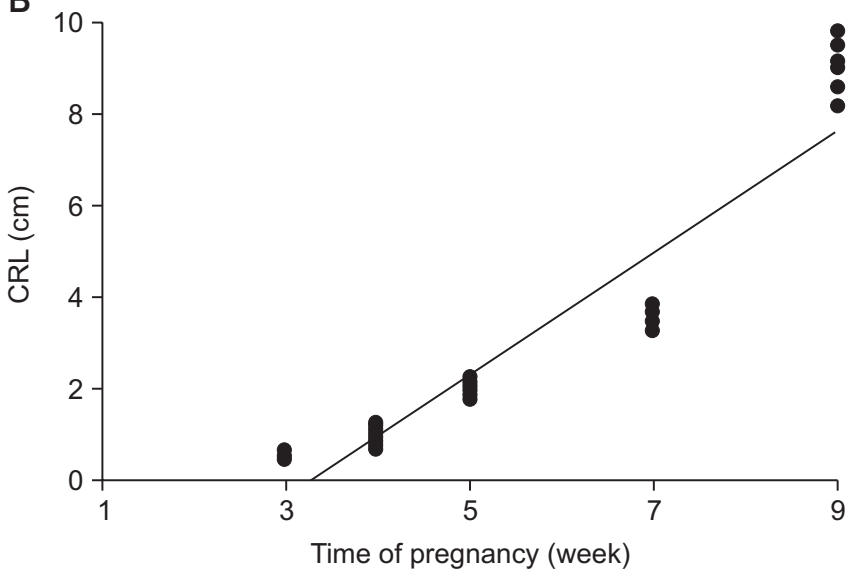

Fig. 1. The crown-rump length and gestational age of conceptus. (A) The crown-rump length (mean \pm SD) of conceptus estimated at different time points of pregnancy, $(B)$ relationship between $C R L$ and stages of pregnancy in the Black Bengal goat $\left(R^{2}=0.89, p<0.05\right)$.
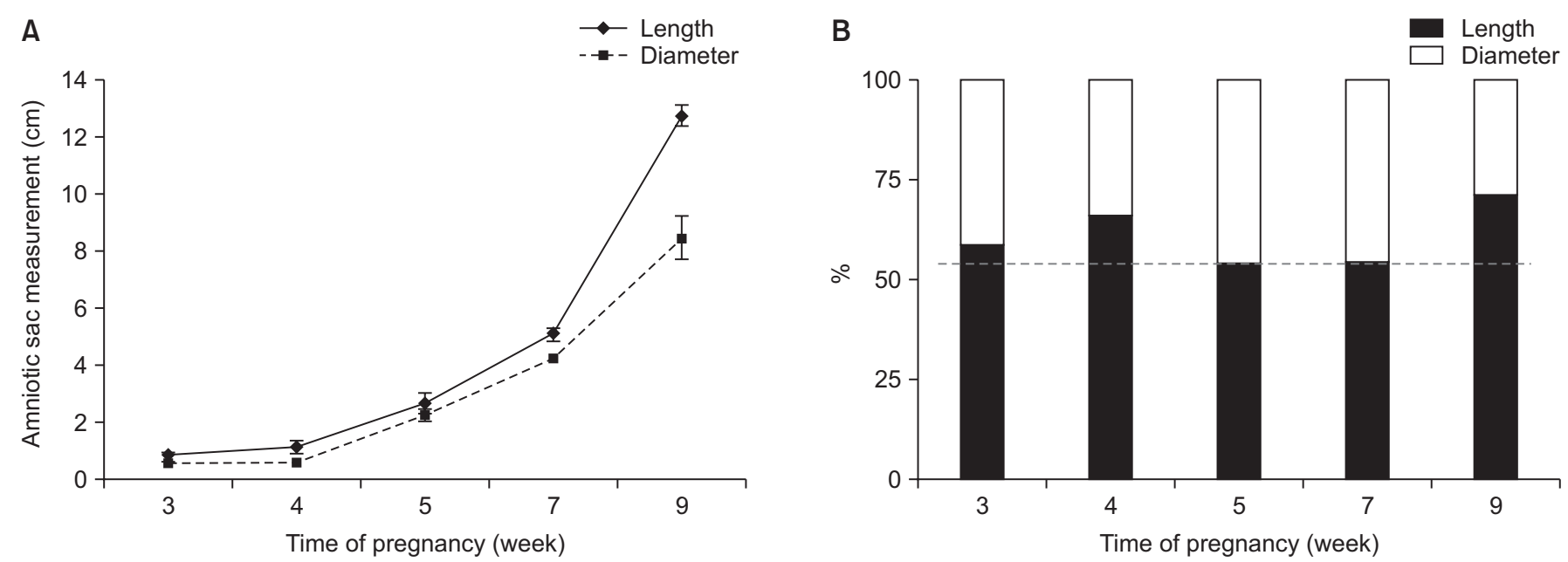

Fig. 2. Amniotic sac measurements in the Black Bengal goat. (A) Amniotic sac measurements (length and diameter) at different time points of pregnancy in goats. (B) Relative \% of length and diameter of amniotic sac at different time points of pregnancy in goats.

Table 1. Changes in uterine size (length and diameter) at different time points of pregnancy period in the Black Bengal goat

\begin{tabular}{cccccc}
\hline \multirow{2}{*}{$\begin{array}{c}\text { Weeks of } \\
\text { pregnancy }\end{array}$} & \multicolumn{2}{c}{\begin{tabular}{c} 
Length \\
\cline { 2 - 3 } \cline { 5 - 6 }
\end{tabular}} & $\begin{array}{c}\text { Deft hometer } \\
(\mathbf{c m})\end{array}$ & & \multicolumn{2}{c}{$\begin{array}{c}\text { Length } \\
(\mathbf{c m})\end{array}$} & & $\begin{array}{c}\text { Diameter } \\
(\mathbf{c m})\end{array}$ & $\mathbf{( c m )}$ \\
\hline $3(n=4)$ & $20.0 \pm 1.5$ & $6 \pm 0.5$ & & $21.0 \pm 1.0$ & $7.0 \pm 0.8$ \\
$4(n=6)$ & $21.5 \pm 2.0$ & $6.5 \pm 0.7$ & & $22.0 \pm 1.2$ & $7.0 \pm 0.3$ \\
$5(n=4)$ & $24.5 \pm 1.8$ & $10.0 \pm 1.2$ & & $26.0 \pm 2.0$ & $11.5 \pm 1.5$ \\
$7(n=4)$ & $28.5 \pm 2.1$ & $20.0 \pm 2.0$ & & $34.5 \pm 2.1$ & $21.0 \pm 2.0$ \\
$9(n=4)$ & $43.0 \pm 2.3$ & $13.5 \pm 1.4$ & $37.0 \pm 1.7$ & $16.0 \pm 1.1$ \\
\hline
\end{tabular}

$\mathrm{n}=$ number of uterus.

The length and diameter of the amniotic sac at 3 weeks of pregnancy were $0.9 \pm 0.1 \mathrm{~cm}$ and $0.6 \pm 0.0 \mathrm{~cm}$, respectively. Both the length and the diameter of amniotic sacs increased proportionally with the advancement of pregnancy at 9 weeks and measured $12.8 \pm 0.4 \mathrm{~cm}$ and $8.5 \pm 0.8 \mathrm{~cm}$, respectively (Fig. $2 \mathrm{~A}$ ). Importantly, there was no change between the length and the diameter of amniotic sacs during 5 and 7 weeks of pregnancy (Fig. 2B). The photographs of amniotic sacs at different time points of pregnancy are presented in Fig. 3 .

The mean volume of allantoic fluid was recorded $19.0 \pm$ $3.0 \mathrm{~mL}$ at 5 weeks of pregnancy and then it increased rapidly, 3-folds higher at 7 weeks $(60.0 \pm 5.0 \mathrm{~mL})$ and then began to decline gradually to $50.0 \pm 5.0 \mathrm{~mL}$ at 9 weeks of pregnancy (Fig. 4). On the other hand, the amniotic fluid was constantly increased from $3.4 .0 \pm 0.3 \mathrm{~mL}$ ( 5 weeks) to $21.0 \pm 2.0 \mathrm{~mL}$ and $111.5 \pm 4.0 \mathrm{~mL}$ at 7 weeks and 9 weeks of pregnancy, respectively. Of note, there was no effect of 

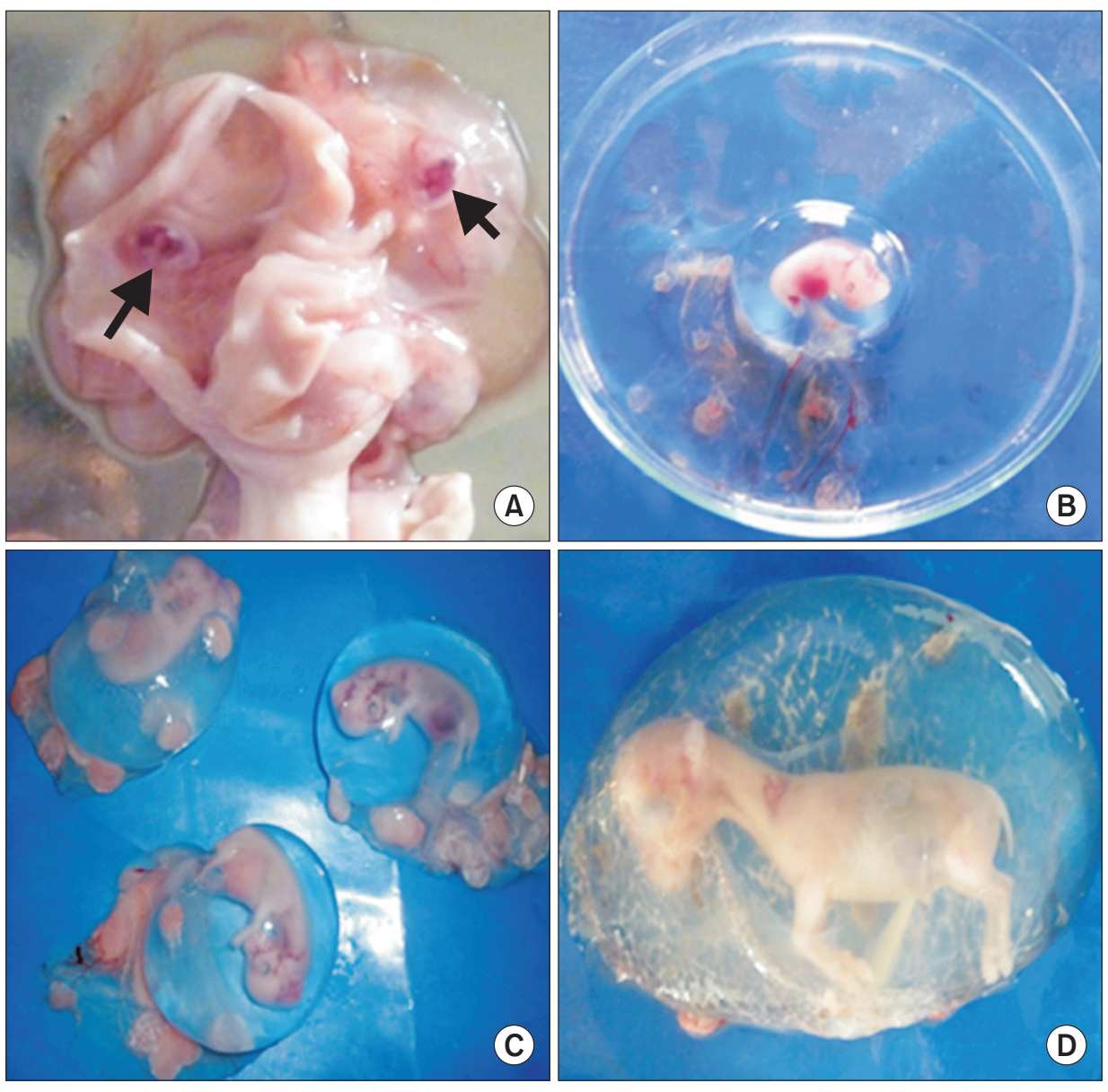

Fig. 3. Amniotic sac at different time points of pregnancy in goats. (A) 3 weeks (B) 5 weeks (C) 7 weeks, and (D) 9 weeks.

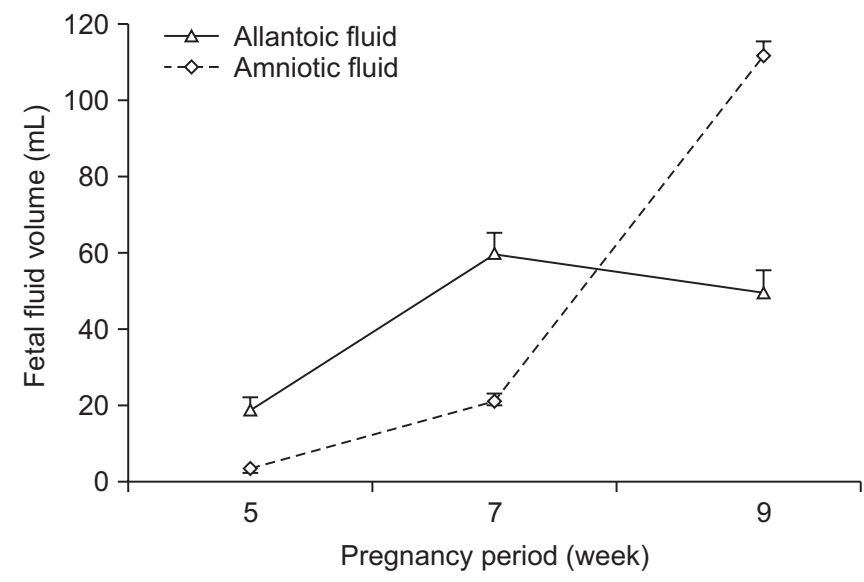

Fig. 4. Volume (mean \pm SD) of fetal fluid formed by individual conceptus at different time points of pregnancy in goats.

conceptus number on allantoic and aminiotic fluid volume.

The cotyledons were first appeared on allanto-chorionic surface of conceptus from 4 to 5 weeks of pregnancy. The closed eye, nostril and hooves of the conceptus became visible at 7 weeks of pregnancy.

\section{DISCUSSION}

The present study has focused on the early conceptus development in the Black Bengal goats and provided the basic information related to changes of growth and development of conceptus with gradual progress of pregnancy period, which may help to distinguish between normal and abnormal pregnancy in the Black Bengal goat.

The crown-rump length (CRL) is the measurements of length of embryo and fetus from the top of head (crown) to the bottom of buttock (rump). It is typically determined from an ultrasonographic image and can be used to estimate the gestational age. In the present study, we determined CRL by direct measurement on the conceptuses for estimation of their probable age. In our study, the CRL of conceptus was found gradually increasing with the advancement of pregnancy period, which is expected because of gradual growth and development of internal organs, for example the heart and the lungs. Similarly, it was observed that the lengthwise growth rate of embryo 
from 30 days of pregnancy and onward is approximately linear in Norwegian breeds of goat (Lyngset, 1971) and Egyptian Baladi goats (Amer, 2008).

In the current study, both the left and the right uterine horns were gradually increased in almost similar pattern with the advancement of pregnancy irrespective of the number of conceptuses present in each horn. The result also revealed that the diameter of both uterine horns was remarkably increased from 5 weeks of pregnancy and onward. It has been reported that volume of uteri increases with the fetal age in sheep that is in agreement with our findings (Robinson et al., 1977; Mufti et al., 2000). Uterine distensions have also been reported during pregnancy in sheep (Wani and Buchoo, 1990).

The amniotic sac is a cavity formed by amniotic membranes, commonly called as water bag, in which the embryo/fetus grows and develops until birth. In the present study, size of amniotic sac gradually increased with the fetal age. It was also observed no difference between length and diameter of amniotic sac from 5 to 7 weeks of pregnancy, suggesting that the amniotic sacs maintain spherical shape in this particular stage of pregnancy in goats. The reason behind this feature remains to be elucidated. Interestingly, it has been demonstrated that the fetal membranes grow more rapidly than the fetus itself to meet its impending biological requirements during the early stages of pregnancy in the Iranian goats (Khojasteh, 2012).

In the present study, we observed that allantoic fluid production was gradually increased until 7 weeks and then progressively reduced. The decreasing tendency of amount of allantoic fluid from 7 weeks of pregnancy might allow the rapid production of amniotic fluid from 7 weeks of pregnancy to further. The amniotic fluid helps to cushion the conceptus from bump and injury and allows the fetus to move freely inside the uterus. Similar to our findings, it was reported that the amount of amniotic fluid gradually increases with the advancement of pregnancy period in the Sahel goats (Waziri et al., 2012).

In the present study, the maternal influence (age, parity, body condition etc.) on the growth and development of the conceptus during early pregnancy was ignored. The study was carried out on the samples obtained from slaughterhouses. Thus, age, parity and body condition of mother goats were unknown; however, such factors might influence the growth and development of the conceptus, which requires further investigation.

\section{CONCLUSION}

This study has provided the basic information about the gradual changes in conceptus development in the Black Bengal goat breed. The data obtained from this study can be useful for better understanding of physiology of early pregnancy in goat and to differentiate between normal and abnormal development of conceptus during early pregnancy period. Further study is recommended to investigate the detail conceptus development during entire gestation period in Black Bengal goat by inseminating the goats and collecting the samples after slaughtering of the animals in a time-dependent manner.

\section{CONFLICTS OF INTEREST}

No potential conflict of interest relevant to this article was reported.

\section{ACKNOWLEDGEMENTS}

The authors would like to thank authorities of respective slaughterhouses for providing the sample materials used in this study.

\section{AUTHOR CONTRIBUTIONS}

AKT conceived, designed, performed the experiments and drafted the manuscript. MAR participated in sampling of slaughterhouse materials and helped in conducting experiments. MNH participated in conducting the experiments. MTI helped in data analysis. ANMAR edited the manuscript. ZCD participated in the experimental design and edited the manuscript.

\section{AUTHOR'S POSITION AND ORCID NO.}

\author{
AK Talukder, Associate Professor, \\ https://orcid.org/0000-0001-6904-8801 \\ MA Rahman, Associate Professor, \\ https://orcid.org/0000-0003-1317-3608 \\ MN Hoque, Assistant Professor, \\ https://orcid.org/0000-0002-4861-0030 \\ MT Islam, Associate Professor, \\ https://orcid.org/0000-0002-6245-808X
}


ANMA Rahman, Professor,

https://orcid.org/0000-0002-7678-7829

ZC Das, Associate Professor, https://orcid.org/0000-0002-2413-0526

\section{REFERENCES}

Amer HA. 2008. Determination of first pregnancy and foetal measurements in Egyptian Baladi goats (Capra hircus). Vet. Ital. 44:429-437.

Argüello A. 2011. Trends in goat research, a review. J. Appl. Anim. Res. 39:429-434.

Bangladesh Economic Review. 2018. Finance Division, Ministry of Finance, Government of the People's Republic of Bangladesh.pp. 109.

Chowdhury SA, Bhuiyan MSA, Faruk S. 2002. Rearing black bengal goat under semi-intensive management 1. Physiological and reproductive performances. Asian-Aust. J. Anim. Sci. 15:477-484.

Greyling JP. 2000. Reproduction traits in the Boer goat doe. Small Rumin. Res. 36:171-177.

Husain SS, Horst P, Islam ABMM. 1996. Study on the growth performance of Black Bengal goats in different periods. Small Rumin. Res. 21:165-171.

Khojasteh SMB. 2012. Prenatal development of Iranian goat fetuses. Int. Res. J. Appl. Basic Sci. 3:2022-2024.

Lyngset O. 1971. Studies on reproduction in the goat. VII. Pregnancy and the development of the foetus and the foetal accessories of the goat. Acta Vet. Scand. 12:185-201.

Martínez MF, Bosch P, Bosch RA. 1998. Determination of early pregnancy and embryonic growth in goats by transrectal ultrasound scanning. Theriogenology 49:1555-1565.

Mellado M, Amaro JL, García JE, Lara LM. 2000. Factors affecting gestation length in goats and the effect of gestation period on kid survival. J. Agric. Sci. 135:85-89.

Mufti AM, Wani GM, Wani NA, Buchoo BA, Khan MZ. 2000. Prenatal development of ovine fetus. Small Rumin. Res. 38:87-89.

Robinson JJ, McDonald I, Fraser C, Crofts RMJ. 1977. Studies on reproduction in prolific ewes: I. Growth of the products of conception. J. Agric. Sci. 88:539-552.

Talukder AK, Rahman A, Islam T, Rahman ANA. 2015. Biometry of genitalia, incidence of gynecological disorders and pregnancy loss in Black Bengal Goat: an abattoir study. J. Emb. Trans. 30:51-57.

Wani GM and Buchoo BA. 1990. Laparoscopic view of ovine conceptus. Indian J. Anim. Sci. 60:564-568.

Waziri MA, Sivachelvan N, Ribadu AY. 2012. Pregnancy related sequential changes of the foetal fluids and foetal positioning in Sahel goats. Niger. Vet. J. 33:531-539. 